\title{
Fatores Familiares e Desempenho Escolar: Uma Abordagem Multidimensional*
}

\author{
Maria Teresa Gonzaga Alves ${ }^{1}$ \\ Maria Alice Nogueira ${ }^{1}$ \\ Cláudio Marques Martins Nogueira ${ }^{1}$ \\ Tânia de Freitas Resende ${ }^{1}$ \\ ${ }^{1}$ Universidade Federal de Minas Gerais (UFMG), Minas Gerais, Brasil
}

\section{INTRODUÇÃO}

\begin{abstract}
influência da família no desempenho escolar dos filhos constitui objeto de estudo da Sociologia da Educação desde, pelo menos, o período do pós-Segunda Guerra Mundial. Na década de 1950 e início dos anos 1960, grandes levantamentos estatísticos foram realizados com o objetivo de identificar as variáveis associadas às disparidades de rendimento escolar entre os alunos. Os resultados, de forma geral, destacaram o meio sociofamiliar como um poderoso fator, focalizando, sobretudo, os dados posicionais do grupo familiar (renda, ocupação e escolaridade dos pais, raça etc.) e suas características morfológicas (número de filhos, sexo, ordem de nascimento, dentre outros) (Nogueira, 1998).
\end{abstract}

Nos anos 1960-1970, com a hegemonia das teorias da reprodução, a família continua sendo um elemento importante nas análises das desigualdades escolares, enfatizando-se, agora, o patrimônio cultural por ela transmitido ou as aspirações escolares em seu seio suscitadas, tudo isso em conformidade com sua posição de classe. A partir da década de

\footnotetext{
* Os autores agradecem o apoio da Fundação Ford e do Instituto Nacional de Estudos e Pesquisas Educacionais Anísio Teixeira do Ministério da Educação (Inep/MEC) a esta pesquisa.
}

DADOS - Revista de Ciências Sociais, Rio de Janeiro, vol. 56, no-3, 2013, pp. 571 a 603. 
1980, o lugar central da família nos estudos sociológicos em educação consolida-se com a emergência do que se passou a designar como a "sociologia das relações família-escola". As pesquisas na área, que têm se multiplicado desde então, passam a investigar as dinâmicas internas e os processos de socialização familiares, buscando apreender as disposições e as estratégias desenvolvidas pelos pais no que tange à vida escolar dos filhos, além de analisar de que forma esses elementos contribuem para configurar diferentes destinos escolares (Lahire, 1997).

O presente artigo pretende contribuir para essa longa tradição de estudos, discutindo resultados de uma pesquisa que investigou a influência das condições e dinâmicas familiares sobre o desempenho de alunos dos anos iniciais do ensino fundamental. A originalidade da pesquisa, especialmente no contexto brasileiro ${ }^{1}$, consiste justamente na tentativa de averiguar simultaneamente uma grande gama de fatores que compõem um conjunto representativo das principais variáveis apontadas pela literatura: desde as clássicas características posicionais e morfológicas do grupo familiar até os aspectos mais sutis recentemente focalizados pelos sociólogos, como as concepções educacionais dos pais e as práticas desenvolvidas cotidianamente pelas famílias. É de se destacar que a investigação relativa a esses últimos aspectos tem assumido um caráter predominantemente qualitativo, ao passo que, no presente estudo, o desafio é o de tentar apreender algumas dessas variáveis de forma quantitativa. Além disso, a pesquisa também inova ao associar as variáveis coletadas diretamente junto às famílias, por meio de questionário, com a proficiência escolar dos alunos, obtida por meio de testes padronizados.

Tal abordagem foi possível por se tratar de uma investigação articulada ao Projeto Geres - Estudo Longitudinal da Geração Escolar 2005, pesquisa que acompanhou, de 2005 a 2008, a evolução da proficiência escolar de cerca de 21 mil alunos do ensino fundamental de cinco cidades brasileiras, por meio da aplicação de cinco "ondas" de testes de língua portuguesa e de matemática - a primeira realizada no início de 2005, quando os alunos começavam a $1^{a}$ série, e as demais, aplicadas no final da 1aㅡ, da 2ª , da 3aㅡ e da $4 \stackrel{a}{\text { a }}$ séries $^{2}$.

Para a presente pesquisa, construiu-se uma subamostra a partir da amostra Geres de Belo Horizonte, a qual abrangia 4.611 alunos do Ensi- 
no Fundamental, matriculados em estabelecimentos de ensino públicos e privados ${ }^{3}$.

Com o objetivo de tornar nossa amostra mais homogênea quanto à origem social, o primeiro passo foi excluir, dessa população, o quintil superior em termos socioeconômicos. Supusemos que isso permitiria verificar, com maior precisão, o efeito, sobre o desempenho dos filhos, de diferenças secundárias entre as famílias (processos socializadores, modos de relação com a escola, entre outras). Em outras palavras, supunha-se que uma variação excessiva no perfil socioeconômico das famílias tenderia a explicar quase completamente as diferenças de desempenho escolar, eclipsando o impacto dos aspectos menos visíveis da influência familiar. Desse modo, nossa amostra concentrou-se basicamente nas classes populares e nas frações inferiores das classes médias. Após esse procedimento, efetuou-se uma estratificação das famílias por tipos de estabelecimento de ensino frequentado (escola federal, escolas privadas, escolas estaduais e municipais comuns e escolas estaduais e municipais destacadas), diferenciados segundo critérios que serão discutidos na seção intitulada Modelo 2: Tipo de Escola. Finalmente, mantendo a proporção entre os estratos delimitados, foram selecionados 300 alunos cujas famílias passaram a constituir a amostra a ser investigada. Houve perda amostral de um caso, tendo sido efetivamente interrogadas 299 famílias.

O instrumento de coleta de dados foi um questionário constituído de 145 itens de resposta objetiva, aplicado, em 2007, a um dos genitores (em geral a mãe), por meio de entrevista diretiva. Obteve-se, assim, um banco de dados bastante abrangente, incluindo as respostas de todos os itens do questionário e a proficiência dos alunos em quatro ondas de testes Geres, o qual vem sendo tratado estatisticamente.

Uma parte desse tratamento consistiu em agrupar variáveis ordinais do questionário em fatores, utilizando uma técnica estatística multivariada denominada Análise Fatorial Confirmatória (AFC) ${ }^{4}$. A AFC é usada para testar hipóteses teóricas e/ou empíricas sobre como as variáveis se agrupam na população (Muthén e Muthén, 2006). No caso desta pesquisa, havia hipóteses teóricas baseadas nas dimensões familiares que a sociologia das relações família-escola vem associando à escolaridade dos filhos, que serão discutidas na próxima seção deste artigo. 
Na AFC encontramos um bom ajuste do modelo, e os fatores extraídos foram incluídos no banco de dados da pesquisa ${ }^{5}$. São eles: conhecimento do sistema de ensino; posse de bens culturais; práticas cotidianas de escrita; ordem racional doméstica; práticas familiares de leitura; ambição escolar; interação pais / filhos; acompanhamento do dever de casa; ações na escolha do estabelecimento de ensino; modos de exercício da autoridade parental ${ }^{6}$.

O objetivo deste artigo é analisar a associação desses fatores com o desempenho dos alunos. Foram ajustados vários modelos de regressão linear, nos quais a proficiência dos alunos em língua portuguesa, na onda 1, foi tomada como variável dependente, e os fatores familiares, como variáveis independentes. Decidiu-se pela utilização da primeira onda por ser ela a menos sujeita: a) a um eventual efeito-escola; e b) a perdas amostrais ocorridas nas ondas subsequentes do projeto Geres. Todavia, houve uma perda amostral de 16 alunos que não possuem proficiência na onda 1, embora tenham proficiências nas outras ondas. Mas nessas as perdas são sempre maiores às da onda 1 . Assim, os casos considerados nas análises subsequentes se referem a 283 alunos e as suas proficiências na primeira onda Geres. É lícito supor que o intervalo temporal entre essa onda e a aplicação dos questionários não tenha prejudicado as análises, uma vez que trabalhamos com disposições familiares que, sabidamente, se modificam lentamente no tempo ${ }^{7}$.

Inicialmente, foram testados dois modelos: o primeiro, um modelo de regressão simples, no qual o nível socioeconômico das famílias é a única variável independente (modelo 1); e o segundo, que acrescenta ao primeiro as variáveis indicadoras do tipo de escola frequentada (modelo 2). Este último foi tomado como modelo básico. Em seguida, foram construídos 11 modelos nos quais os fatores familiares foram incorporados, um de cada vez, ao modelo básico. O propósito desses modelos parciais é o de estimar o efeito isolado de cada um dos fatores no desempenho do aluno. Oito desses modelos tiveram um bom ajuste, com coeficientes significativos para os fatores testados (modelos 3 ao 9) ${ }^{8}$.

Finalmente, foi ajustado um modelo incluindo todos os fatores que apresentaram coeficientes significativos na etapa anterior, o qual denominaremos "modelo final". Para constituí-lo, utilizamos uma técnica de seleção de subconjuntos de variáveis denominada stepwise, que consiste em testar as variáveis independentes, em diferentes combina- 
ções e ordens, até se chegar ao melhor ajuste, no qual apenas algumas variáveis permanecem.

Na próxima seção, serão discutidos os resultados dos modelos 1 e 2, e dos modelos parciais, 3 ao 9, a partir de uma breve síntese dos referenciais teóricos que orientaram a construção do questionário e justificaram a introdução de cada um dos modelos no estudo ${ }^{9}$. Em seguida, será realizada uma análise do modelo final. A Tabela 1, no final da seção, sintetiza os parâmetros obtidos em todos os modelos, ou seja, os coeficientes de regressão das variáveis e os coeficientes de determinação $\left(R^{2}\right)$ que medem a qualidade do ajuste dos modelos. No Apêndice, figuram a descrição das variáveis incluídas nos modelos e suas estatísticas descritivas básicas, além da explicação dos modelos estatísticos de regressão.

\section{RESULTADOS}

\section{Modelo 1: nível socioeconômico (NSE)}

A associação entre desempenho escolar e posição social é talvez a mais importante e duradoura tese da Sociologia da Educação (Coleman et al., 1966). Por isso, esse fator não poderia deixar de ser considerado, mesmo com a relativa homogeneização socioeconômica da amostra, operada mediante a exclusão das famílias da população Geres pertencentes ao quintil mais alto de NSE.

Neste artigo, assume-se que o NSE é um construto latente que expressa a relação entre as dimensões nível de instrução e ocupação dos pais, além da renda familiar, esta última medida de forma direta ou indireta pelo padrão de consumo de bens e serviços da família ${ }^{10}$. O Gráfico 1 apresenta a relação entre o NSE das 299 famílias e a proficiência dos alunos na onda 1. Cada ponto no gráfico representa um aluno. Nota-se que há uma relação linear positiva entre as duas variáveis, haja vista que a proficiência aumenta à medida que cresce o NSE. A linha, ajustada por meio de uma equação de regressão linear simples, sintetiza essa relação. Os pontos estão mais concentrados em torno da linha, mas, obviamente, eles não caem exatamente na linha. $\mathrm{O}$ resultado do ajuste deste modelo indica que o NSE "explica" 23\% da proficiência $\left(R^{2}=0,23\right.$ na Tabela 1$)^{11}$. Permanece ainda uma substancial variabilidade nos resultados, motivo pelo qual procuramos formular modelos mais complexos. 


\section{Gráfico 1}

Relação entre Proficiência em Leitura Onda 1 e NSE

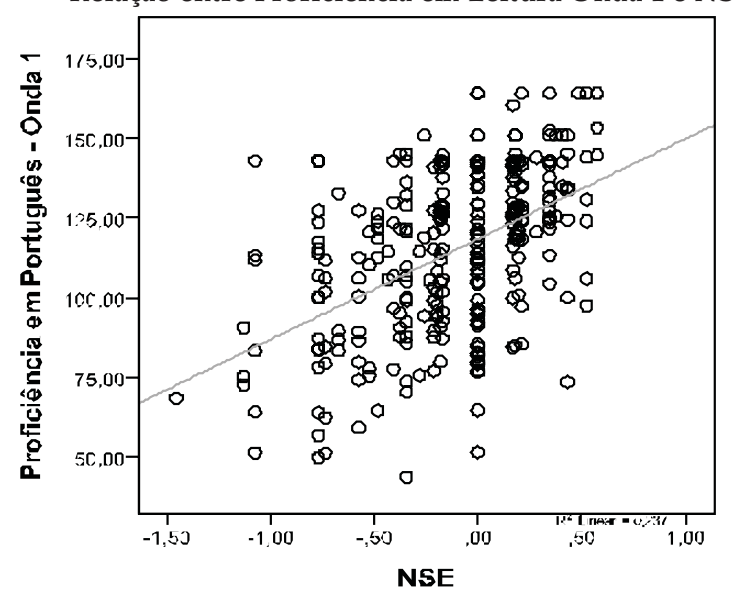

Fonte: Elaboração própria com dados da pesquisa.

Obs.: A descrição das variáveis está na Tabela 1, no Apêndice.

\section{Modelo 2: tipo de escola}

O sistema educacional brasileiro é bastante hierarquizado quanto à distribuição de oportunidades escolares. As instituições de educação básica mantidas pelo governo federal são reconhecidas pela excelência do seu ensino. Entretanto, elas têm um número muito limitado de vagas, e o acesso é bastante restrito. As escolas particulares, por sua vez, são uma opção apenas para as famílias com melhores condições socioeconômicas. Para a maioria das famílias, as escolas públicas estaduais e municipais constituem a única opção ${ }^{12}$.

Todavia, esse último segmento também não é homogêneo: algumas instituições de ensino estaduais e municipais se distinguem pela reputação de boa qualidade. Os critérios de distinção, no entanto, costumam ser difusos, tais como a percepção do perfil dos alunos, o ambiente disciplinado, a fama sobre a qualidade do ensino etc. (Costa, 2008; 2010). Esses atributos acabam por atrair famílias dispostas a competir por suas vagas.

O fenômeno da disputa por vagas nas escolas públicas de maior prestígio tem sido estudado por meio de uma categoria de análise denominada "quase mercado escolar oculto" (Costa e Koslinski, 2011;2012). A despeito das políticas de setorização da matrícula impostas às famílias, estas se utilizam de estratégias muitas vezes veladas para conse- 
guir a vaga almejada. As escolas, por seu lado, também de forma velada, podem adotar mecanismos, mais ou menos lícitos, para selecionar alunos. Essas práticas, do lado da demanda e da oferta, contribuem para reforçar a hierarquia entre as instituições de ensino públicas.

Em Belo Horizonte, as vagas nas escolas públicas são distribuídas - via "cadastro escolar" - pelo critério de proximidade da residência do aluno. Partimos da hipótese de que algumas famílias, mais mobilizadas, agiam de forma velada para contornar o cadastro escolar e garantir que seus filhos fossem designados para escolas públicas conhecidas por seu prestígio ${ }^{13}$. O interesse pelo fenômeno da mobilização familiar justificou assim a distinção entre escolas estaduais e municipais comuns e destacadas.

Uma vez que a "reputação" das escolas não é um atributo diretamente observado, as escolas destacadas foram definidas como aquelas cujas médias estão situadas no quintil superior do conjunto de médias da Prova Brasil de $2005^{14}$. Assim, no modelo 2 e subsequentes, foram considerados quatro tipos de escolas, cujas proporções estão na Tabela 1, do Apêndice: (1) escolas estaduais e municipais comuns; (2) escolas estaduais e municipais destacadas; (3) escola pública federal; e (4) escolas privadas. A primeira categoria foi tomada como referência.

O modelo 2 apresentou bom ajuste, com substancial melhora na explicação da proficiência, haja vista que a inclusão das variáveis indicadoras dos tipos de escola aumentou o coeficiente de determinação $\left(R^{2}\right.$ ajustado = 0,34), ou seja, os tipos de escolas e o NSE, juntos, "explicam" $34 \%$ da variabilidade da proficiência. Na análise dos fenômenos sociais, quando se utilizam informações no nível dos indivíduos, valores dessa magnitude podem ser considerados muito bons.

Para avaliar a pertinência da distinção entre escolas públicas destacadas e comuns, testou-se também um modelo convencional apenas com as redes de ensino ${ }^{15}$. O resultado praticamente não mudou $\left(R^{2}\right.$ ajustado $=0,33$ ). Uma vez que a separação dessas escolas nos permite obter resultados muito mais elucidativos sobre as nossas questões de pesquisa, manteve-se a distinção. A mesma estratégia analítica foi utilizada por F. Alves (2010), em estudo com os dados do projeto Geres na cidade do Rio de Janeiro, e se revelou crucial para o entendimento das escolhas educativas das famílias que matriculam os filhos na rede pública. 
Considerando este modelo 2 como básico, ou seja, assumindo suas variáveis como controle, foram testados na sequência, um a um, os fatores de interesse da pesquisa. ${ }^{16}$

\section{Modelo 3: conhecimento do sistema de ensino}

O modelo 3 testa o efeito do fator "conhecimento do sistema de ensino" na proficiência, com o controle do NSE e dos tipos de escola. Observa-se, na Tabela 1, que o modelo melhora a explicação da variação dos resultados dos alunos $\left(R^{2}\right.$ ajustado $\left.=0,38\right)$ e o coeficiente associado ao fator, como esperado, está positivamente associado à proficiência. Esse construto foi medido por meio de seis itens do questionário que buscavam captar o conhecimento dos pais sobre a qualidade das escolas de ensino básico e superior da cidade de Belo Horizonte ${ }^{17}$ e sobre a existência de faculdades gratuitas, além de três questões gerais, a saber: "o que é vestibular?", "o que é o Enem"? "o que é o Prouni"?

Esse fator, também denominado "capital informacional" por alguns autores (Millete e Thin, 2005; Van-Zanten, 2009; Brandão, Mandalert e Paula, 2005), refere-se à detenção, pela família, de um conjunto de conhecimentos e informações pertinentes sobre a organização e o funcionamento interno da instituição escolar, seus valores e hierarquias, seus métodos e linguagens etc., os quais constituiriam vantagens altamente rentáveis no mercado escolar ou, em outros termos, no processo de produção do valor que a escola confere ao aluno; valor esse que se expressa, sobretudo, em seus resultados acadêmicos, em particular nas notas a ele atribuídas.

De um modo geral, o papel do capital cultural da família no sucesso escolar dos filhos já foi fartamente demonstrado por toda uma literatura sociológica de âmbito internacional que se seguiu à publicação das primeiras obras de Bourdieu e Passeron $(1964 ; 1970)$ que, pioneiramente, a partir dos anos 1960, postularam a importância fundamental desse fator na explicação das desigualdades sociais de escolarização.

Na tentativa de conhecer as mediações pelas quais esse tipo de riqueza familiar impacta o desempenho escolar, Bourdieu (1998a) detectou três diferentes modalidades que o capital cultural pode assumir, a saber:

a) uma forma dita "incorporada" porque se integra ao corpo de uma pessoa, passando a fazer parte de suas propriedades físicas (ex.: postu- 
ras corporais, esquemas mentais, conhecimentos, habilidades linguísticas, preferências estéticas etc.);

b) uma forma dita "objetivada" porque se materializa na forma de bens palpáveis que representam a cultura dominante (ex.: livros, obras de arte e todos os outros suportes materiais de cultura, como computadores etc.);

c) uma forma dita "institucionalizada" porque atesta o reconhecimento institucional de competências culturais (ex.: o diploma).

Já em inícios da década de 1960, Bourdieu via no que hoje se chama de capital informacional uma dimensão importante do capital cultural em seu estado "incorporado", defendendo que as informações sobre o mundo da escola e sobre os percursos escolares constituem "a parte do capital cultural que é a mais diretamente rentável na vida escolar" (Bourdieu, 1998b:44). O que o levava a tal afirmação era a convicção de que as famílias possuidoras de tais informações as convertem em trunfos na medida em que - com base nessas informações - logram realizar os investimentos escolares mais rentáveis, na forma da escolha adequada - e no momento certo - do estabelecimento de ensino, do curso, das opções curriculares etc.

Porém, só mais recentemente é que os sociólogos começaram a esmiuçar essas condutas estratégicas, passando a observar como, no dia a dia da vida doméstica, os genitores - particularmente, as mães (Establet, 1987) - mobilizam seu patrimônio de conhecimentos na organização de um apoio pedagógico permanente que dá suporte, complementa e amplia a ação cognitiva da escola.

Esses estudos vêm demonstrando que, cada vez mais informados - inclusive em virtude do surgimento de uma indústria de publicações mais ou menos especializadas e do contato mais frequente com outros genitores (informações "quentes") -, alguns pais "desenvolvem um acompanhamento mais estreito e mais adaptado às exigências da escola" e às características escolares dos filhos (Van Zanten, 2009:106). E que, em suma, eles assumem um papel pedagógico paralelo ao da escola, o qual abrange atividades como: "explicar novamente as aulas"; "criar, a partir de livros didáticos, jogos para reforçar e desenvolver os conhecimentos escolares" (Duru-Bellate Van Zanten, 2006:165); “estender e enriquecer os deveres de casa"; "transmitir métodos de trabalho" (Van Zanten, 2009:105-106), entre tantos outros. Sem falar do fato 
de que são os pais mais "informados" que são os mais "aptos" a "dominar as situações de interação" com os profissionais da escola e a "desenvolver projetos individuais", visando à boa escolaridade dos filhos (Duru-Bellat e Van Zanten, 2006:174).

\section{Modelo 4: posse de bens culturais}

O modelo 4 testa o fator "posse de bens culturais" e, tal como o modelo anterior, o coeficiente estimado é significativo e no sentido esperado, além de também apresentar a mesma qualidade do ajuste. Esse construto foi medido por meio de dez itens do questionário relativos à existência no domicílio de bens como: dicionários, enciclopédias, atlas, livros de literatura, livros infantis, jornais, revistas, computador com acesso à internet etc.

Como se viu no item anterior, trata-se aqui do estado "objetivado" do capital cultural que se expressa na posse, pela família, de bens e suportes materiais de cultura que são capazes de exercer um efeito positivo sobre o rendimento escolar. Mais especificamente, este fator diz respeito ao acesso domiciliar da criança a materiais culturais e paradidáticos como: enciclopédias, dicionários, atlas, calculadoras, jogos, brinquedos e CD-ROMs educativos, internet etc.

É evidente que essa forma de capital cultural é altamente dependente dos recursos econômicos da família, mas ela depende também de seus "valores intrínsecos" (Soares e Collares, 2006:621) que configuram um estilo de vida e orientam a aquisição deste ou daquele tipo de bens de consumo. Como este último ponto diz respeito diretamente ao estado "incorporado" do capital cultural, é lícito concluir que a detenção de recursos financeiros é condição necessária, mas não suficiente para garantir o capital cultural "objetivado".

Além disso, segundo Bourdieu (1998a), a característica mais marcante dessa última forma de capital cultural reside no fato de que sua simples propriedade legal não garante seu efetivo usufruto cultural, o qual, mais uma vez, depende do capital cultural "incorporado", que é condição da "apropriação", ou seja, condição para que se tire proveito intelectual desse recurso.

Portanto, para que haja ganho cognitivo decorrente dos bens materiais de cultura disponíveis na residência (e supostamente reconvertidos em rendimento escolar), é preciso ainda que existam na família dispo- 
sições culturais que ativem de modo simbólico essa forma de riqueza cultural, na forma de seu uso e de seu "bom" uso.

As pesquisas de Lahire, em meios populares franceses, ilustram esse ponto. Nelas, ele se defrontou com situações em que objetos comprados com muito sacrifício financeiro pelas famílias permaneciam como "letra morta", um "patrimônio cultural morto, não-apropriado, in-apropriado" porque os pais não desempenhavam o "papel de intermediários" entre os filhos e os bens de cultura, não "conseguiam acompanhá-los na descoberta desses objetos" (cf. Lahire, 1994:91), "não desenvolviam estratégias de apropriação dos textos pelos filhos" (idem:92), na medida em que: eles mesmos nunca forneciam o exemplo próprio de utilização desses materiais; evidenciavam sua pouquíssima familiaridade com eles; ou, até mesmo, dificultavam seu uso, em nome da boa conservação material de objetos dispendiosos.

\section{Modelo 5: práticas cotidianas de escrita}

O modelo 5 atesta o valor significativo do índice composto pelas variáveis relacionadas às "práticas cotidianas de escrita". A qualidade do ajuste do modelo que incluiu esse fator é equivalente à dos modelos parciais analisados até aqui.

A Sociologia da Educação já reconhece há muito tempo a importância da familiaridade com a norma culta da língua, particularmente na sua forma escrita, como um dos fatores favorecedores do sucesso escolar (Forquin, 1995; Bautier, 2011). Na verdade, a discussão sobre o papel do domínio da norma culta da língua na constituição das desigualdades frente à escola é uma especificação da discussão mais ampla, sintetizada acima nas seções, Conhecimento do Sistema de Ensino e Posse de Bens Culturais, sobre os efeitos escolares da posse familiar do capital cultural. A escola esperaria de seus alunos e premiaria em seus processos avaliativos o domínio de uma determinada variante da língua, aquela constituída historicamente em sintonia com a emergência do texto escrito e que é legitimada oficialmente, entre outras coisas, por meio da imposição de uma norma gramatical única (Lahire, 1993). Esse padrão linguístico dominante não estaria distribuído na população de modo aleatório, mas, ao contrário, seria próprio das camadas sociais mais favorecidas, justamente aquelas que já tiveram contatos anteriores mais significativos com o mundo da leitura e da escrita. Tem-se, assim, a constatação de um círculo vicioso, no qual aqueles historica- 
mente menos impregnados pela cultura ou, mais especificamente, pela linguagem valorizada pela escola têm menores chances de serem bem-sucedidos no interior das escolas e, assim, de superarem suas desvantagens.

Inspirados, sobretudo, pela abordagem de Lahire (1997), buscamos investigar o impacto dos usos menos formais da escrita no cotidiano familiar, usos muitas vezes nem mesmo reconhecidos como práticas de escrita, seja por parte dos pesquisadores, seja pelos próprios sujeitos. Assim, consideramos se as famílias fazem lista de compras antes da ida ao supermercado, se utilizam agenda ou listam as tarefas diárias, se fazem planejamento, por escrito, das despesas de cada mês, se mantêm caderno de receitas, se deixam bilhetes escritos uns para os outros e, finalmente, se redigem e-mails e cartas.

Lahire salienta que essa presença não explícita da escrita no cotidiano familiar pode impactar positivamente a escolarização dos filhos basicamente de duas formas. A primeira, mais evidente, consiste numa preparação informal da criança para os usos da escrita que lhe serão exigidos no âmbito escolar. $\mathrm{O}$ argumento é o de que as crianças que já convivem com a escrita em seu cotidiano familiar estariam mais aptas a atender, com facilidade e naturalidade, às expectativas e exigências do uso escolar da escrita.

Mas a hipótese central de Lahire é a de que o uso da escrita no cotidiano familiar teria ainda um impacto indireto e mais difuso sobre a escolarização das crianças, ao favorecer a emergência de disposições mais racionais relativas ao uso do tempo, ao planejamento e organização das atividades diárias e até mesmo à ordenação do próprio pensamento. Na pesquisa, investigamos os possíveis efeitos de uma racionalização do cotidiano familiar por meio de um índice próprio ("ordem racional doméstica"), discutido a seguir.

\section{Modelo 6: ordem racional doméstica}

O modelo 6, também com bom ajuste, corrobora - por método quantitativo - a tese sustentada por Lahire sobre o impacto positivo que um ambiente familiar racionalmente ordenado pode ter sobre o desempenho escolar.

Conforme apontado no item anterior, Lahire (1997:21) observa que certas formas de presença da escrita no cotidiano familiar (agenda, lista 
de compras, lista de coisas a fazer, livro de contas, caderno de receitas, caderneta de endereços, lembretes, bilhetes etc.) estão associadas a "uma gestão mais racional, mais calculada e, com isso, menos imediata e menos espontânea das atividades familiares". A escrita funcionaria nesses casos como um instrumento de ordenação da vida cotidiana, favorecendo o cálculo dos gastos e a previsão das despesas domésticas, o estabelecimento de horários para as diferentes atividades, o cumprimento de compromissos, a comunicação eficiente entre os membros da família ou desses com outras pessoas, a contenção de impulsos de consumo imediatos e o planejamento e a realização de projetos de mais longo prazo.

Haveria, portanto, em certas famílias, um ordenamento mais racional da vida cotidiana, favorecido pelo uso da escrita. Esse ordenamento se evidenciaria, por um lado, na gestão da vida econômica da família e, por outro, no que ele chama de ordem moral doméstica. Em relação à dimensão econômica, tenderia a prevalecer nessas famílias o planejamento, a previsão, o cálculo, o estabelecimento de metas prioritárias e um esforço de poupança, com vistas à realização de objetivos de longo prazo. No que se refere à chamada ordem moral doméstica, Lahire observa que são famílias nas quais existem regras claras em relação ao comportamento dos filhos: exigências de cumprimento das tarefas escolares, controle do tempo dedicado à televisão ou à internet, restrições das saídas noturnas e definição de um horário para dormir, entre outras coisas.

A hipótese de Lahire é a de que essa ordem doméstica, material e moral, teria um impacto positivo sobre a escolarização dos filhos na medida em que os prepararia para o cumprimento das regras do jogo escolar, ou para o desempenho do ofício de aluno, como diria Perrenoud (1995). O sucesso escolar depende em parte da capacidade do aluno de se organizar para o cumprimento das tarefas escolares, de distribuir bem o seu tempo, de ser capaz de se esquivar das distrações e se dedicar com responsabilidade às suas obrigações de estudante. $\mathrm{O}$ aluno socializado num ambiente familiar racionalmente ordenado estaria, assim, em clara vantagem.

Em última instância, a tese de Lahire é a de que as ordens material e moral domésticas se traduzem numa ordem cognitiva, que se evidencia não apenas num comportamento mais reflexivo, ponderado, previsível, mas em formas mais racionais de organização do pensamento e 
da linguagem. Ele chama a atenção para o fato de que a produção de um texto explicativo ou argumentativo, componente usual das atividades escolares, supõe a ordenação e o encadeamento lógico, racional, dos argumentos, de modo a construir uma estrutura que faça sentido. Na perspectiva dele, a capacidade de produção desse tipo de ordenamento cognitivo do pensamento e do discurso seria favorecida pela socialização em um ambiente igualmente organizado. O impacto da existência de uma ordem familiar racionalmente organizada se faria sentir, assim, nas duas dimensões principais em relação às quais os alunos são avaliados na escola, a comportamental e a cognitiva.

Nesta pesquisa, em que pese a amplitude da noção de ordem racional doméstica, optamos por nos restringir, na construção do índice relativo a esse tema, às informações obtidas a partir de três questões. A primeira é relativa ao modo como as famílias organizam seus documentos (contas a pagar e já pagas, recibos, documentos pessoais etc.): misturados e em qualquer lugar da casa; misturados, mas em um lugar específico; separados, classificados e colocados em lugares diferentes. A segunda é concernente à capacidade da família de planejar o futuro, estabelecendo e cumprindo objetivos de mais longo prazo. A terceira é relativa ao modo de gestão da vida econômica, verificando a habilidade da família para conter seus impulsos imediatos de consumo, visando economizar parte da renda familiar.

\section{Modelo 7: práticas familiares de leitura}

O modelo para testar as "práticas familiares de leitura" apresenta um coeficiente significativo e positivo para o fator, confirmando, mais uma vez, o conhecimento, já consolidado na área de Sociologia da Educação, da importância da familiaridade com a língua padrão, como um elemento favorecedor do desempenho escolar (Forquin, 1995). Do mesmo modo que na discussão realizada anteriormente, relativa à importância da escrita, é possível argumentar que a presença da leitura no cotidiano familiar prepara a criança para lidar com maior facilidade e naturalidade com todas as práticas escolares nas quais essa habilidade será exigida (Lahire, 1993; Bautier, 2011). É preciso lembrar que, além de ser estudada em si mesma - constituindo, sobretudo nos anos iniciais da Educação Básica, um objeto central do currículo - a leitura é, também, um instrumento necessário para a realização eficiente de todas as demais atividades escolares, incluindo o aprendizado de todos os outros conteúdos disciplinares. 
No âmbito desta pesquisa, investigamos a existência de leitores na família (pai, mãe ou outras pessoas), a frequência de sua prática de leitura (diária, semanal ou mais esparsa) e o tipo de suporte (livros, jornais ou revistas). Averiguamos ainda se os adultos têm o hábito de ler para as crianças e se a família costuma conversar sobre o que lê. Considerando o objetivo de examinar os efeitos das práticas familiares de leitura sobre o desempenho escolar, seria, sem dúvida, importante realizar também uma análise do conteúdo das leituras: verificar quais livros, jornais e revistas são escolhidos e quais seções são selecionadas, no caso dos periódicos e jornais. Essa análise mais detalhada não foi possível, no entanto, nos limites do questionário.

\section{Modelo 8: ambição escolar}

O modelo 8 testa o fator "ambição escolar", e o resultado do ajuste desse modelo é comparável ao do modelo 7 . O valor significativo e positivo do coeficiente do fator atesta a importância das aspirações educacionais das famílias nos processos educacionais. No âmbito desta pesquisa, o nível de ambição escolar das famílias foi apreendido a partir de três dimensões: o grau de escolaridade que os pais acham necessário que os filhos alcancem; a idade em que acham que eles devem começar a trabalhar; a importância que atribuem ao ensino superior como elemento definidor de um futuro bem-sucedido.

As grandes pesquisas estatísticas sobre as desigualdades escolares realizadas, nos países desenvolvidos, no período pós-Segunda Guerra Mundial, já apontavam que as famílias não se diferenciavam apenas em relação ao nível de desempenho escolar alcançado por seus filhos, mas igualmente por seu grau de aspiração escolar (Forquin, 1995). Desde então se tem observado, com frequência (Brinbaum, 2011), famílias que têm filhos com resultados escolares equivalentes desenvolverem expectativas bastante diferenciadas e tomarem decisões mais ou menos ambiciosas: parar ou continuar os estudos, optar por ramos de estudos de maior ou menor prestígio, escolher estabelecimentos de ensino mais ou menos seletivos etc. De acordo com a teoria de Bourdieu (1998; 2007), essas diferenças no grau de aspiração escolar são manifestações de um habitus constituído em função das condições objetivas de existência. Em função de sua localização no espaço social -e, portanto, do volume e peso relativo dos diferentes capitais (econômico, cultural, social etc.) no seu patrimônio -, cada grupo social constituiria um conhecimento prático sobre o que está ou não ao seu alcance e sobre as es- 
tratégias mais viáveis a serem utilizadas para garantir a manutenção ou ascensão em relação à posição social ocupada. No que se refere à educação, o grau de aspiração e de investimento das famílias dependeria basicamente do volume de capital cultural possuído, que definiria a probabilidade objetiva do êxito escolar, e do peso relativo desse capital no conjunto do patrimônio familiar, que estabeleceria o quanto a posição social atual ou futura depende especificamente da posse de certificados escolares. Os grupos sociais com maiores chances de alcançar o sucesso escolar e que mais dependem dele para se manter ou ascender socialmente tenderiam a apresentar níveis de aspiração e graus de investimento mais elevados na escolarização dos seus filhos. É tipicamente o caso das classes médias. Inversamente, aqueles grupos cujo sucesso escolar é menos provável, pela falta do capital cultural, ou que dependem menos desse sucesso, por possuírem outros recursos, tenderiam a apresentar graus de aspiração e investimento escolares menos acentuados. É, respectivamente, o caso das classes populares e das elites econômicas.

É interessante observar que, embora existam críticas importantes ao modo como Bourdieu concebe o processo de constituição das aspirações em relação à escola, e que sejam propostas teorias alternativas, não parece existir uma contestação frontal da importância desse fator como elemento a ser considerado na explicação das desigualdades escolares. O modelo teórico de Boudon (1979; 2000), por exemplo, classicamente contraposto ao de Bourdieu, sustenta que o nível de aspiração não seria estabelecido de maneira tão durável por um suposto processo de socialização, do qual resultaria o habitus, mas que seria fruto de uma avaliação racional por parte dos atores, refeita a cada momento, em função das condições objetivas em que se encontram, dos custos, riscos e benefícios do investimento escolar. A discordância aqui é, sobretudo, em relação ao grau de estabilidade dos níveis de aspiração e ao modo mais ou menos consciente e racional como esses são estabelecidos. No entanto, no que concerne à relevância desse fator para a explicação das desigualdades escolares, Boudon lhe confere uma importância ainda maior do que o faz Bourdieu. Segundo ele, enquanto as diferenças de sucesso escolar, relacionadas ao nível de capital cultural familiar, afetam as trajetórias escolares basicamente nos anos iniciais de estudo, as diferenças de orientação, diretamente associadas aos níveis de aspiração escolar, afetariam todo o percurso de escolarização. 


\section{Modelo 9: interação pais/filhos}

O modelo 9 confirma que a "interação pais / filhos" é positivamente associado à proficiência. $\mathrm{O}$ fator foi composto a partir dos seguintes itens do questionário: conversas dos pais com o filho sobre a escola, sobre o que o filho vê na TV, sobre o que lê, sobre o que os pais leram, sobre o futuro; prática de algum esporte junto com o filho; realização de jogos (dama, jogos infantis, baralho etc.) e passeios (parques, praças, sítios, museus e exposições) com o filho.

Coleman (1997) é um dos autores cujas abordagens fundamentaram a construção desse fator. Ele destaca, como um dos componentes do background familiar, o capital social, o qual, referente às relações no contexto familiar ${ }^{18}$, incluiria, dentre outros aspectos, a presença física dos adultos e a atenção por eles dispensada às crianças, em interações que permitem a elas o acesso ao capital humano (representado pela escolaridade) dos pais ou parentes próximos, ou que podem até mesmo compensar a falta de capital humano.

Alguns trabalhos recentes vêm demonstrando a variação dos estilos de interação entre pais e filhos conforme a classe social, o nível de instrução dos pais, o tipo de família, a divisão de papéis educativos entre pai e mãe, dentre outros. Conforme Le Pape e Van Zanten (2009), vários estudos apontam que, nos meios populares, as relações entre pais e filhos são mais hierarquizadas, com fronteiras mais claras. Nas classes médias e superiores predomina uma relação mais horizontal, que valoriza a autonomia, a iniciativa, a negociação - valores esses atualmente mais consoantes com as práticas escolares.

Um dos estudos mencionados pelas autoras é o de Lareau (2007). A partir de investigação etnográfica realizada nos Estados Unidos com famílias de classes sociais e grupos étnicos diferentes, essa pesquisadora constatou, na maior parte das famílias de classe média, que os pais envolvem os filhos em um grande número de atividades organizadas e específicas para sua idade, com o objetivo de desenvolver neles habilidades e talentos considerados úteis para a vida. Assim, desenvolvem interações com os filhos nas quais o uso da linguagem e da razão, bem como o diálogo como forma de disciplina, são enfatizados. Esses pais tendem ainda a conversar bastante com os filhos sobre as diferentes situações do cotidiano, estimulando-os a expressar opiniões, ideias e necessidades. Já na maior parte das famílias de classes trabalhadoras e pobres, Lareau e sua equipe não identificaram uma preocu- 
pação específica com o desenvolvimento de talentos ou das habilidades de linguagem e de negociação. Grandes discussões verbais não são frequentes e não se verifica um cuidado particular dos pais com as oportunidades de expressão ou de desenvolvimento do pensamento crítico dos filhos.

Segundo Lareau (2007), as crianças de classes médias, em interações com profissionais como médicos e educadores, mostram-se mais seguras e assertivas do que as crianças das classes trabalhadora e pobre, $\mathrm{o}$ que permite supor que haja desdobramentos desses estilos de educação também no que se refere ao desempenho escolar propriamente dito.

Alguns estudos já realizados no Brasil permitem, também, sustentar a hipótese da relação entre interações pais / filhos e o desempenho escolar. Soares e Collares (2006) trabalharam com dados do Sistema de Avaliação da Educação Básica para avaliar a relação entre recursos familiares e desempenho cognitivo de alunos da 8a série (atual 9o ano) do ensino fundamental. Na discussão dos resultados, destacaram o envolvimento dos pais (indicador que registra o grau de participação dos pais tanto na vida diária quanto no acompanhamento escolar dos filhos, incluindo itens como conversas com os filhos, refeições em comum etc.), atribuindo a ele um "papel de ativação dos recursos culturais" (p. 636) que permitiria concretizar, no desempenho dos alunos, as vantagens econômicas e culturais da família.

Outro estudo, realizado por Bonamino et al. (2010), utilizou dados do Programa Internacional de Avaliação de Estudantes (Pisa), de 2000, para verificar a relação entre os efeitos dos diferentes tipos de capitais e de sua mobilização familiar sobre o desempenho em leitura dos alunos participantes (com idade de 15 anos). Com relação ao capital social, utilizou-se, além de outras variáveis, um indicador de "diálogo familiar" que incluiu itens como: conversas com os filhos sobre assuntos políticos, sociais, sobre livros, filmes, programas de TV, refeições realizadas em conjunto e outros. Os resultados apontaram uma forte correlação entre diálogo familiar e desempenho escolar, sendo que, em média, os estudantes de todos os grupos sociais investigados se beneficiaram de seu efeito positivo.

\section{Modelo final}

Após analisar cada um dos fatores separadamente, investigou-se o efeito de todos os fatores familiares no desempenho do aluno tal como eles 
atuariam conjuntamente na realidade social, segundo os referenciais analíticos anteriormente discutidos. Entretanto, a transposição da teoria para o modelo estatístico esbarra no limite da técnica utilizada neste trabalho. Sabe-se que muitos desses fatores apresentam forte correlação entre si. Ou seja, embora as dimensões familiares focalizadas na pesquisa sejam teoricamente sólidas e tenham sido empiricamente confirmadas, por meio de análises prévias, esses fatores poderiam, uma vez misturados em um modelo de regressão múltipla, se confundir. Nesse caso, a presença concomitante de todos eles, ao contrário de melhorar o ajuste do modelo, pode produzir coeficientes não significativos.

Há várias técnicas estatísticas que auxiliam a construção de modelos de regressão mais complexos e com muitas variáveis independentes. Utilizamos aqui uma técnica denominada stepwise, que testa, em passos sequenciais, subconjuntos alternativos de variáveis até que se chegue ao melhor ajuste ${ }^{19}$.

Para a construção desse modelo, foram necessários seis passos. No primeiro, a variável que individualmente apresentou o maior coeficiente de regressão foi "conhecimento do sistema de ensino". Ela resistiu aos testes subsequentes até o modelo final, no qual permaneceram, além dela, o NSE, as três indicadoras do tipo de escola (pública destacada, pública federal e escola privada) e a "posse de bens culturais".

Esse modelo final, cuja síntese se encontra na última coluna da Tabela 1 , ao final desta seção, apresentou o maior coeficiente de determinação $\left(R^{2}\right.$ ajustado $\left.=0,39\right)$, o que significa que essas variáveis juntas "explicam" 39\% variação na proficiência. Além disso, todos os coeficientes de regressão, como esperado, são positivos e significativos. Assim, o coeficiente do NSE indica que, a cada incremento nesse indicador, o aluno ganha em média 9,6 pontos na escala de proficiência Geres.

Quanto ao tipo de escola, a leitura do resultado deve considerar a escola comum como referência. Dessa forma, um aluno que estuda na escola pública destacada obtém, em média, 6,7 pontos a mais do que obteria, se estudasse em uma escola pública comum; um aluno que estuda na escola pública federal ganha, em média, 13,2 pontos a mais do que ganharia se estudasse em uma escola pública comum; e um aluno que estuda em uma escola privada obtém, em média, 21,1 pontos a mais do que obteria se estudasse em uma escola pública comum ${ }^{20}$. 
Maria Teresa Gonzaga Alves et al.

Tabela 1

Síntese dos Coeficientes de Regressão (*)

\begin{tabular}{|c|c|c|c|c|c|c|c|c|c|c|}
\hline & Mod1 & Mod2 & Mod3 & Mod4 & Mod5 & Mod6 & Mod7 & Mod8 & Mod9 & $\begin{array}{l}\text { Mod } \\
\text { Fina } \\
\end{array}$ \\
\hline Constante & 118,3 & 105,9 & 106,1 & 106,5 & 106,6 & 106,7 & 106,4 & 106,2 & 106,5 & 106,4 \\
\hline NSE & 31,5 & 18,5 & 10,4 & 11,6 & 13,7 & 14,9 & 17,9 & 14,1 & 16,0 & 9,6 \\
\hline $\begin{array}{l}\text { Pública } \\
\text { destacada }\end{array}$ & & 7,3 & 6,8 & 6,8 & 7,0 & 6,8 & 7,4 & 6,7 & 7,2 & 6,7 \\
\hline $\begin{array}{l}\text { Pública fe- } \\
\text { deral }\end{array}$ & & 18,8 & 14,2 & 14,1 & 14,8 & 15,5 & 17,2 & 15,7 & 16,2 & 13,2 \\
\hline Privada & & 25,3 & 21,7 & 21,9 & 22,2 & 22,4 & 24,2 & 23,7 & 23,2 & 21,1 \\
\hline $\begin{array}{l}\text { Conheci- } \\
\text { mento do } \\
\text { sistema de } \\
\text { ensino }\end{array}$ & & & 8,6 & & & & & & & 4,9 \\
\hline $\begin{array}{l}\text { Posse de } \\
\text { bens cultu- } \\
\text { rais }\end{array}$ & & & & 7,5 & & & & & & 4,7 \\
\hline $\begin{array}{l}\text { Práticas co- } \\
\text { tidianas de } \\
\text { escrita }\end{array}$ & & & & & 6,3 & & & & & \\
\hline $\begin{array}{l}\text { Ordem ra- } \\
\text { cional do- } \\
\text { méstica } \\
\end{array}$ & & & & & & 6,5 & & & & \\
\hline $\begin{array}{l}\text { Práticas fa- } \\
\text { miliares de } \\
\text { leitura }\end{array}$ & & & & & & & 4,8 & & & \\
\hline $\begin{array}{l}\text { Ambição } \\
\text { Escolar }\end{array}$ & & & & & & & & 6,2 & & \\
\hline $\begin{array}{l}\text { Interação } \\
\text { pais / fi- } \\
\text { lhos }\end{array}$ & & & & & & & & & 4,2 & \\
\hline \multicolumn{11}{|l|}{$\begin{array}{l}\text { Concepção } \\
\text { de infância } \\
\end{array}$} \\
\hline $\mathbf{R}^{2}$ ajustado & 0,24 & 0,34 & 0,38 & 0,38 & 0,37 & 0,37 & 0,36 & 0,36 & 0,35 & 0,39 \\
\hline
\end{tabular}

Fonte: Elaboração própria com dados da pesquisa.

(*) Todos os coeficientes são significativos ( $p=0.05)$

Os dois fatores das dimensões familiares que permaneceram no modelo final têm coeficientes positivamente associados à proficiência. Observa-se que, a cada incremento na escala do fator "posse de bens culturais", o aluno ganha em média 4,7 pontos; e, em relação ao fator "conhecimento do sistema de ensino", o efeito é de 4,9 pontos. 
O significado desses valores torna-se mais claro quando os situamos na escala Geres, na qual se espera que, a cada ano de escolaridade, os alunos ganhem em média 50 pontos. Portanto, os resultados do modelo final evidenciam a grande vantagem dos alunos matriculados na rede particular de ensino, mesmo na presença de outros fatores. Este último fato torna-se ainda mais contundente quando se tem em mente que o segmento da rede privada considerado nesta pesquisa não se destaca por um alto padrão de excelência escolar e, por isso, não deve ser confundido com o segmento que atende as elites culturais e econômicas $^{21}$.

Quanto aos fatores familiares que permaneceram no modelo final, uma maneira de examinar seu efeito consiste em compará-lo com o modelo 2, ou seja, com o modelo que contém apenas as variáveis de controle. Nota-se assim que, no modelo final, a "posse de conhecimentos sobre o sistema de ensino" e a "posse de bens culturais" afetam mais fortemente os coeficientes do NSE e da escola pública federal (redução no valor do coeficiente em $48 \%$ e $30 \%$, respectivamente). No caso da escola privada, a redução do coeficiente fica num patamar intermediário (16\%) e no da escola pública destacada a redução é muito menor $(6 \%)$.

Embora se saiba que a escolaridade dos pais constitui um dos itens sintetizados no NSE e represente uma das formas do capital cultural, a redução no valor do coeficiente de regressão na presença dos fatores "informações sobre o sistema escolar" e "posse de bens culturais" indica que essas outras dimensões do capital cultural podem "compensar" o NSE das famílias. A evidência sugere que se trata de dimensões independentes, mas que colaboram, em conjunto, para o desempenho dos alunos.

Quanto à escola pública federal, a redução de seu coeficiente de regressão, no modelo final, em comparação com o coeficiente do modelo 2, indica que as famílias usuárias dessa instituição de ensino são mais bem aquinhoadas em relação aos atributos familiares - acima referidos - escolarmente rentáveis para os alunos. Essa escola pertence a uma grande universidade federal, o que lhe garante um prestígio local. Porém, o sistema de ingresso se dá por meio de sorteio, o que, em princípio, deveria produzir certa aleatoriedade no perfil sociocultural das famílias contempladas. Entretanto, o resultado deste estudo coloca dúvidas sobre isso. A vantagem dos alunos dessa escola, em relação aos 
alunos das escolas públicas comuns, é impulsionada em parte porque eles têm mais probabilidade de pertencer a famílias com mais alto capital informacional ${ }^{22}$ e mais elevada posse de bens culturais. Assim, um aluno da escola federal, dadas as características de sua família, poderia compensar a vantagem de um aluno da escola privada menos dotado desses atributos familiares. Esse resultado vem confirmar estudo recente (Resende, Nogueira e Nogueira, 2011) que demonstra que as famílias da escola federal fizeram escolhas mais acadêmicas do que práticas, ao optar pelo estabelecimento de ensino. Isso evidencia que a aleatoriedade da população submetida ao sorteio é apenas relativa.

A ausência, no modelo final, de efeitos significativos para os outros fatores - não obstante os efeitos significativos observados quando eles foram analisados um de cada vez, juntamente com as variáveis de controle - não deve ser interpretada como se eles fossem irrelevantes. De fato, o efeito relativo de múltiplos fatores é algo muito difícil de ser calculado, pois depende não apenas do número de casos e de variáveis, mas também da correlação entre elas. Todavia, os resultados dos fatores analisados individualmente, à luz da teoria sociológica sobre a relação família-escola, fornecem boas pistas para o conhecimento das dinâmicas familiares e de suas consequências para o rendimento escolar, o que justifica a continuidade desse programa de investigação.

\section{CONSIDERAÇÕES FINAIS}

O programa de pesquisa do qual decorre este artigo constitui uma tentativa de contribuir com as investigações que buscam avaliar a influência das famílias no desempenho escolar dos filhos, a partir de diferentes níveis de análise ou escalas de observação. A partir dos anos 1980, observa-se uma proliferação de estudos microssociológicos sobre a relação família-escola (baseados em análises de trajetórias, realização de entrevistas, observações), os quais, colocando esse objeto em evidência no campo da sociologia da educação, têm produzido uma grande quantidade de resultados que, embora revelando nuances importantes dos processos de construção das desigualdades escolares, correm o risco de gerar uma dispersão de dados que não contribuem para compreender as configurações mais gerais desses processos na estrutura social.

Diante dessa constatação, a pesquisa em pauta neste texto buscou reunir, em um mesmo instrumento de resposta objetiva, diferentes variá- 
veis familiares que vêm sendo apontadas pela literatura como influentes no desempenho escolar dos filhos, a fim de ponderar seus efeitos relativos e verificar como interagem na configuração das desigualdades de desempenho dos alunos investigados. Para isso, assumiu-se o desafio de abordar, por meio de questionário, construtos que vêm sendo elaborados a partir de abordagens predominantemente qualitativas, na busca de confirmá-los (ou não) quantitativamente. Os resultados encontrados confirmam a significância, para essa análise, de aspectos como: o NSE familiar; o tipo de estabelecimento de ensino frequentado; o capital de conhecimentos sobre o sistema de ensino; a posse de objetos culturais; as práticas cotidianas de escrita; a racionalização da vida doméstica; as práticas familiares de leitura; a ambição escolar parental; as interações entre pais e filhos.

Uma das principais contribuições deste trabalho consiste em testar esses fatores em um contexto no qual - além do controle do NSE e do tipo de escola - configurou-se uma relativa homogeneização da amostra no que refere aos aspectos socioeconômicos. Ou seja, para além da velha contraposição entre elites, classes médias e classes populares, o que se encontra são diferenças e desigualdades entre as famílias, no interior de um grupo bastante próximo em termos de macroclassificações socioeconômicas - pertencente às camadas médias baixas e às camadas populares.

Como se viu, ao serem incluídos em um mesmo modelo, nem todos os fatores testados se mantiveram significantes, o que em absoluto invalida sua importância individual. Não se trata, portanto, de afirmar que aqueles fatores que não tiveram significância no modelo final não tenham efeito sobre o desempenho; pode ocorrer que, na presença de diversas variáveis inter-relacionadas, o modelo não consiga estimar esse efeito adequadamente, especialmente porque, nesse caso, busca-se explicar as variáveis no mesmo nível de correlação. Uma perspectiva que se abre para trabalhos futuros com a mesma base de dados é a realização de modelos de equações estruturais, que possam incluir e explorar ideias de causalidade entre os fatores.

Da mesma forma, o fato de alguns itens presentes no questionário não terem se mantido como fatores após a Análise Fatorial Confirmatória (como foi o caso de "concepção sobre brincadeiras" e "atividades extraescolares"), ou terem se mantido, mas com conteúdo teoricamente insatisfatório (como foi o caso de "concepções sobre a infância"), ou ainda de fatores confirmados na AFC não terem se mostrado significa- 
tivos nos modelos de regressão realizados (como "acompanhamento do dever de casa", "ações na escolha da escola" e "autonomia/heteronomia") não exclui sua relevância para outros estudos quantitativos e qualitativos. Alguns desses fatores, como "concepção sobre brincadeiras" e "autonomia/heteronomia" referem-se justamente a aspectos difíceis de serem captados por questões objetivas, sendo necessário um aperfeiçoamento dos instrumentos a fim de efetuar sua análise com maior segurança.

Ainda com relação aos resultados do trabalho e considerando o modelo final, um aspecto que chama a atenção é o forte efeito do tipo de escola frequentada, o que mais uma vez confirma a perversa desigualdade interna ao sistema educacional brasileiro, ainda longe de lograr uma escola pública realmente democrática no sentido de oferecer ensino de qualidade para todos. No caso deste trabalho, os dados se mostram mais contundentes quando se considera que a amostra, formada basicamente por famílias de camadas médias baixas ou de classes populares, não inclui nenhuma criança matriculada nas escolas de maior prestígio de Belo Horizonte. De fato, as escolas privadas envolvidas no estudo são, em sua maioria, instituições de pequeno porte que, até certo ponto, "disputam" alunos com o setor público. Ainda assim, a diferença de proficiência identificada ao se passar da escola pública comum para a escola privada foi muito significativa.

Finalmente, vale ressaltar que, se na pesquisa que gerou este texto se fez um movimento de tentar apreender quantitativamente variáveis até então abordadas predominantemente de modo qualitativo, o "jogo de espelhos" teórico-metodológico (Brandão, 2008) pressupõe, agora, que se busque refinar as análises com uma nova etapa de investigações, na qual um subgrupo de famílias de nossa amostra possa ser ouvido em profundidade. Como vem apontando a literatura sobre desigualdades sociais de escolarização, é claramente na configuração de diferentes fatores no interior de um mesmo caso (Lahire, 1997) que se encontra a explicação para situações de sucesso e de fracasso escolar. $O$ estudo qualitativo permitirá, assim, compreender melhor o sentido das diferentes respostas, analisar as configurações específicas e aproximar-nos do sentido das ações detectadas, neste tratamento estatístico, de modo agregado.

(Recebido para publicação em abril de 2012)

(Reapresentado em junho de 2013)

(Aprovado para publicação em agosto de 2013) 


\section{NOTAS}

1. Em que pese a recente publicação do livro de Barbosa (2009) que explorou a relação entre desempenho escolar de alunos de escolas públicas de Belo Horizonte e o capital social familiar.

2. Para maiores informações sobre o Projeto Geres, consultar Franco, Brooke e Alves (2008).

3. No plano amostral do Projeto Geres, a base para a seleção da amostra do setor privado incluiu apenas estabelecimentos de ensino com até três turmas para cada série. Assim, os grandes colégios privados da cidade, inclusive os de maior prestígio, não estão representados.

4. Como as variáveis são ordinais, o ajuste do modelo da AFC foi feito com um estimador robusto do software MPLUS denominado Mean and variance-adjusted weighted least squares estimator (WLSMV), que utiliza correlação policórica (Muthén e Muthén, 2006).

5. Essa etapa da pesquisa foi realizada por meio de consultoria estatística ao projeto dada pelo professor Daniel Seabra Matos, da Universidade Federal de Ouro Preto. Para os interessados, o relatório técnico com informações sobre o tipo de estimador utilizado, os itens testados em cada fator, os índices de ajustes utilizados, a qualidade do ajuste, os níveis de significância e de precisão das estimativas pode ser requisitado a Maria Teresa Gonzaga Alves, uma das autoras deste artigo.

6. Acrescente-se, ainda, que foram testados também os seguintes fatores: "concepção sobre brincadeiras", "atividades extraescolares" e "concepção de infância". Entretanto, os dois primeiros não se mantiveram como fatores após a AFC. O último se manteve, mas com apenas dois dos itens considerados teoricamente relevantes para o entendimento dessa dimensão. Nesse caso, avaliou-se que o fator extraído, embora confirmado estatisticamente, produziu um construto difícil de ser justificado. Tais problemas podem ter resultado da formulação de itens do questionário, de especificidades da amostra ou de outras contingências. Faz-se assim necessário realizar novas tentativas de estudos quantitativos e qualitativos dessas dimensões.

7. De toda forma, testes realizados com a $3^{\mathbf{a}}$ onda (a última realizada antes da aplicação do questionário) geraram resultados convergentes.

8. As exceções foram os modelos relativos aos fatores acompanhamento do dever de casa, ações na escolha do estabelecimento de ensino e modos de exercício da autoridade parental. Em vista desse resultado e por razões de espaço, esses fatores não serão discutidos neste texto.

9. Evidentemente, a seleção desses referenciais teóricos não esgota a produção no campo da sociologia das relações família-escola, refletindo as perspectivas dos autores e obedecendo aos limites de espaço deste artigo.

10. A metodologia para a construção do fator "nível socioeconômico (NSE)" do Projeto Geres está descrita em Alves e Soares (2009).

11. O emprego das aspas adverte dos riscos de uma leitura determinista dos modelos de regressão. Nas Ciências Sociais, o uso mais adequado dos modelos de regressão deve consistir na análise da associação entre uma variável resposta (ou dependente) e variáveis independentes (chamadas de covariáveis).

DADOS - Revista de Ciências Sociais, Rio de Janeiro, vol. 56, nº 3, 2013 


\section{Maria Teresa Gonzaga Alves et al.}

12. De acordo com a Sinopse Estatística da Educação Básica, em 2011, as escolas federais detinham $0,5 \%$ das matrículas na educação básica; as escolas particulares, $15,5 \%$; e as escolas estaduais e municipais, 38,2\% e 44,7\%, respectivamente. Informações em http:/ / portal.inep.gov.br/basica-censo (acesso em 15 de agosto de 2013).

13. Esta hipótese é deduzida de uma pesquisa finalizada em 2006, cujos resultados foram publicados posteriormente (Alves, M.T.G., 2010).

14. A "Prova Brasil" é uma avaliação de rendimento escolar realizada pelo Instituto de Estudos e Pesquisas Educacionais Anísio Teixeira (Inep/MEC) a cada dois anos. Participam da avaliação alunos do $5^{\circ}$ e $9 \underline{0}$ ano do ensino fundamental de todas as escolas públicas urbanas do país que tenham mais de 20 alunos nas séries avaliadas. Os resultados, por escola e por município, são divulgados no portal do Inep, no ano seguinte à aplicação dos testes.

15. Cabe destacar que os alunos que participaram do projeto Geres não fizeram a Prova Brasil, a qual foi aplicada aos alunos que estavam no final da primeira etapa do Ensino Fundamental, isto é, quatro anos à frente da população de alunos da presente pesquisa. As médias da Prova Brasil foram utilizadas, portanto, como um indicador do nível de qualidade da instituição escolar e não do nível de proficiência do aluno.

16. Em estudos dessa natureza, costuma-se considerar também, como variáveis de controle, o sexo, a cor/raça e a adequação idade série do aluno, porque esses atributos são reconhecidos na literatura educacional como associados ao desempenho escolar (Barbosa, 2009). Entretanto, análises estatísticas prévias (Teste T e ANOVA) não mostraram diferenças significativas entre as proficiências dos alunos na primeira onda segundo as categorias das variáveis "sexo" e "idade adequada para a série". O teste com a variável cor/raça do aluno revelou diferença entre as proficiências dos alunos brancos comparados aos alunos não brancos, porém, com significância fraca e que não persistiu nos modelos de regressão que incluíram a variável NSE.

17. O conhecimento dos pais sobre a qualidade das escolas foi avaliado solicitando aos respondentes que indicassem as melhores escolas e Universidades de Belo Horizonte. As respostas foram cotejadas com os resultados de cada instituição na Prova Brasil e/ou no Enem, no caso da educação básica. No caso do ensino superior, Universidade Federal de Minas Gerais (UFMG) e Pontifícia Universidade Católica de Minas Gerais (PUC-MG) foram tomadas pelos pesquisadores como as instituições de mais alta performance da cidade.

18. Coleman (1997) também considera como parte do capital social familiar a rede de relacionamentos da família, que não enfatizamos aqui por ser menos relevante para a análise do fator em questão. Observa-se que o conceito de capital social de Coleman é diferente do que foi construído por Bourdieu (1998c). Para uma comparação entre ambos, ver Bonamino et al. (2010).

19. A dinâmica computacional do modelo stepwise consiste em introduzir inicialmente a variável que apresenta o maior coeficiente positivo ou negativo na associação com a variável dependente e, em cada passo subsequente, adicionar a variável com a maior correlação parcial, testando-as para decidir sobre a remoção ou permanência no modelo (Norusis, 2005).

20. Tal como no modelo 2, testou-se, no modelo final, o tipo de escola sem fazer distinção entre escolas públicas comuns e destacadas. Isso resultou em coeficientes com valores menores para as escolas particulares e a escola federal (9,3 e 17,1, respectivamen- 
te) em relação às escolas estaduais e municipais em conjunto - tomadas como referência - e um pequeno aumento no coeficiente do nível socioeconômico $(11,0)$. A mudança nos coeficientes é esperada, uma vez que a hierarquização entre as escolas ficou menos acurada. Não houve mudança no nível de significância e valores dos coeficientes dos demais fatores.

21. Além das restrições impostas à amostra do setor privado (cf. nota 2), procedeu-se também à eliminação das famílias do quintil superior em termos socioeconômicos (conforme exposto no item Introdução), onde os alunos das escolas privadas de alto prestígio se fazem mais bem representados.

22. O fato dessas famílias deterem informações sobre a existência de um colégio de aplicação dentro de uma universidade federal, sobre sua forma de recrutamento dos alunos e sobre as condições gerais do sorteio representa, por si só, um elemento do capital informacional. 


\section{Maria Teresa Gonzaga Alves et al.}

\section{REFERÊNCIAS BIBLIOGRÁFICAS}

ALVES, Fátima. (2010), “Escolhas Familiares, Estratificação Educacional e Desempenho Escolar: Quais as Relações". Dados, vol. 53, no 2, pp. 447-468.

ALVES, Maria Teresa G. (2010), “Dimensões do Efeito Escola: Explorando as Interações entre Famílias e Estabelecimentos de Ensino". Estudos em Avaliação Educacional, vol. 21, no 46, pp. 271-296.

ALVES, Maria Teresa G. e SOARES, José Francisco. (2009), “Medidas de Nível Socioeconômico em Pesquisas Sociais: Uma Aplicação aos Dados de uma Pesquisa Educacional". Opinião Pública, vol.15, no 1, pp.1-30.

BARBOSA, Maria Ligia de Oliveira. (2009), Desigualdade e Desempenho: Uma Introdução à Sociologia da Escola Brasileira. Belo Horizonte, Argumentum.

BAUTIER, Élisabeth. (2011), "Linguagem e Diferenciação Social”, in A. Van Zanten (org.), Dicionário de Educação. Petrópolis, Vozes, pp. 551-557.

BONAMINO, Alícia et al. (2010), “Os Efeitos das Diferentes Formas de Capital no Desempenho Escolar: Um Estudo à Luz de Bourdieu e de Coleman". Revista Brasileira de Educação,vol. 15, no 45, pp. 487-499.

BOUDON, Raymond. (1979), L'Inégalité des Chances. Paris, Armand Colin.

. (2000), “Les Causes de l'Inégalité des Chances Scolaires”, in R. Boudon, C.-H. Cuin e A. Massot (orgs.), L'Axiomatique de l'Inegalité des Chances. Paris, L'Harmattan, pp. 9-32.

BOURDIEU, Pierre. (1998), Escritos de educação. Petrópolis, Vozes.

__ (1998a), “Os Três Estados do Capital Cultural”, in Escritos de Educação. Petrópolis, Vozes, pp. 71-79.

. (1998b), "A Escola Conservadora: As Desigualdades frente à Cultura”, in Escritos de Educação. Petrópolis, Vozes, pp. 39-64.

. (1998c), “O Capital Social - Notas Provisórias”, in Escritos de Educação. Petrópolis, Vozes, pp. 65-69.

. (2007), A Distinção: Crítica Social do Julgamento. São Paulo/Porto Alegre, Edusp/Zouk.

e PASSERON, Jean-Claude. (1964), Les Héritiers. Paris, Minuit.

(1970), La Reproduction. Paris, Minuit.

BRANDÃO, Zaia e MANDALERT, Diana; PAULA, Lucília de. (2005), “A Circularidade Virtuosa: Investigação sobre Duas Escolas no Rio de Janeiro". Cadernos de Pesquisa, vol. 35, no 126, pp. 747-758.

BRANDÃO, Zaia. (2008), "Os Jogos de Escalas na Sociologia da Educação”. Educação E Sociedade, vol. 29, № 103, pp. 607-620.

BRINBAUM, Yaël. (2011), “Expectativas das Famílias em Matéria de Educação, in A. Van-Zanten (org.), Dicionário de Educação. Petrópolis,Vozes, pp. 387-389. 
COLEMAN, James S. (1997), "Social Capital in the Creation of Human Capital”, in A. H. Halsey et al. (eds.), Education: Culture, Economy, Society. Oxford, Oxford University Press, pp. 80-95.

_et al. (1966), Equality of Educational Opportunity. Washington D.C., US Government Printing Office.

COSTA, Márcio da. (2008), "Prestígio e Hierarquia Escolar: Estudo de Caso sobre Diferenças entre Escolas em uma Rede Municipal". Revista Brasileira de Educação, vol.13, no 39, pp. 455-469.

. (2010), “Famílias e acesso diferenciado a escolas públicas prestigiadas: um estudo de caso". Educação em Revista, vol. 26, no 2, pp. 227-247.

e KOSLINSKI, Mariane C. (2011), “Quase-mercado Oculto: Disputa por Escolas 'Comuns' no Rio de Janeiro". Cadernos de Pesquisa, São Paulo, vol. 41, no 142, pp. 246-266.

. (2012), "Escolha, estratégia e competição por escolas públicas". Pro-Posições, vol. 23, no 2, pp. 195-213.

DURU-BELLAT, Marie e VAN ZANTEN, Agnès. (2006), Sociologie de l'École (3a. ed.), Paris, Armand Colin.

ESTABLET, Roger. (1987), L'École est-elle Rentable? Paris, PUF.

FORQUIN, Jean-Claude (org.). (1995), Sociologia da Educação - Dez Anos de Pesquisa. Petrópolis, Vozes.

FRANCO, Creso; BROOKE, Nigel e ALVES, Fátima. (2008), “Estudo Longitudinal sobre Qualidade e Equidade no Ensino Fundamental Brasileiro: Geres 2005". Ensaio: Avaliação e Políticas Públicas em Educação, vol.16, no 61, pp. 625-637.

LAHIRE, Bernard. (1993), Culture écrite et inégalités scolaires. Lyon, PUL.

. (1994), “Les Raisons de l'Improbable: Les Formes Populaires de la 'Réussite' à l'École Élémentaire”, in G. Vincent (org.), L'Éducation Prisonnière de la Forme Scolaire? Lyon, PUL, pp.73-106.

(1997), Sucesso Escolar nos Meios Populares: As Razões do Improvável. São Paulo, Ática.

LAREAU, Annette. (2007), “A Desigualdade Invisível: O Papel da Classe Social na Criação dos Filhos em Famílias Negras e Brancas". Educação em Revista, no 46, pp. 13-82.

LE PAPE, Marie-Clémence e VAN ZANTEN, Agnès. (2009), “Les Pratiques Éducatives des Familles", in M. Duru-Bellat e A. Van Zanten (eds.), Sociologie du système éducatif. Les Inégalités Scolaires. Paris, PUF, pp. 185-205.

MILLET, Mathias e THIN, Daniel. (2005), Ruptures Scolaires : L'École à l'Épreuve de la Question Sociale. Paris, PUF.

MUTHÉN, Linda K. e MUTHÉN, Bengt O. (2006), Mplus (version 4.2). Los Angeles, CA, Muthen \& Muthen.

NOGUEIRA, Maria Alice. (1998), “Relação Família-escola: Novo Objeto na Sociologia da Educação". Paidéia, vol. 8, nos 14/15, pp. 91-103.

DADOS - Revista de Ciências Sociais, Rio de Janeiro, vol. 56, nº 3, 2013 
Maria Teresa Gonzaga Alves et al.

NORUSIS, Marija J. (2005), SPSS 13.0: Statistical Procedures Companion. Chicago, Prentice Hall, Inc.

PERRENOUD, Philippe. (1995), Ofício de aluno e sentido do trabalho escolar. Lisboa, Porto.

RESENDE, Tânia de Freitas, NOGUEIRA, Cláudio Marques e NOGUEIRA, Maria Alice. (2011), "Escolha do Estabelecimento de Ensino e Perfis Familiares: Uma Faceta a mais das Desigualdades Escolares". Educação \& Sociedade, vol. 32, no 117, pp. 953-970.

SOARES, José Francisco e COLLARES, Maria Cristina Murta. (2006), “Recursos Familiares e o Desempenho Cognitivo dos Alunos do Ensino Básico Brasileiro". Dados, vol. 49, no 3, pp. 615-650.

VAN ZANTEN, Agnès. (2009), Choisir son École: Stratégies Familiales et Médiations Locales. Paris, PUF. 


\section{APÊNDICE}

\section{Quadro 1}

Variáveis Utilizadas nos Modelos de Análise

\begin{tabular}{|l|l|l|}
\hline Variável & \multicolumn{1}{|c|}{ Tipo } & \multicolumn{1}{c|}{ Descrição } \\
\hline $\begin{array}{l}\text { Proficiência dos alunos em } \\
\text { Leitura - 1 } 1^{-} \text {onda }\end{array}$ & Contínua & $\begin{array}{l}\text { Escala de Proficiência da Pesquisa Geres ob- } \\
\text { tida via Teoria da Resposta ao Item (TRI). }\end{array}$ \\
\hline Nível Socioeconômico (NSE) & Contínua & $\begin{array}{l}\text { Medida obtida via TRI a partir de itens do } \\
\text { questionário dos alunos da pesquisa Geres. }\end{array}$ \\
\hline Escola Pública Federal & Dicotômica & $\begin{array}{l}\text { Indica que o aluno estuda na escola federal: } \\
1=\text { Sim/0 = Não. } \\
\text { A referência é a escola pública comum. }\end{array}$ \\
\hline Escola Pública Destacada & Dicotômica & $\begin{array}{l}\text { Indica que o aluno estuda em escola pública } \\
\text { com nota mais alta na Prova Brasil: } 1=\text { Sim/ } \\
0=\text { Não. } \\
\text { A referência é a escola pública comum. }\end{array}$ \\
\hline Escola Privada & Dicotômica & $\begin{array}{l}\text { Indica que o aluno estuda em escola priva- } \\
\text { da: } 1 \text { = Sim / 0 = Não. } \\
\text { A referência é a escola pública comum. }\end{array}$ \\
\hline Todos os fatores familiares & Contínua & $\begin{array}{l}\text { Escala padronizada obtida via Análise Fato- } \\
\text { rial Confirmatória (AFC). }\end{array}$ \\
\hline
\end{tabular}

\section{Tabela 1}

Estatísticas Descritivas das Variáveis

\begin{tabular}{l|c|c|c|c|c}
\hline & N & Mínimo & Máximo & Média/\% & DP \\
\hline $\begin{array}{l}\text { Proficiência em português na Onda 1 } \\
\text { (Profic) }\end{array}$ & 283 & 43,6 & 164,0 & 114,1 & 25,6 \\
Nível socioeconômico (NSE) após a ex- & 295 & $-1,4$ & 0,6 & $-0,1$ & 0,4 \\
clusão quintil superior & & & & & \\
Conhecimento sobre o sistema escolar & 299 & $-2,2$ & 2,3 & 0,0 & 0,8 \\
Posse de bens culturais & 299 & $-2,5$ & 1,8 & 0,0 & 0,9 \\
Práticas cotidianas de escrita & 299 & $-2,7$ & 1,8 & 0,0 & 0,9 \\
Ordem racional doméstica & 299 & $-2,2$ & 1,8 & 0,0 & 0,8 \\
Práticas familiares de leitura & 299 & $-2,3$ & 2,0 & 0,0 & 0,7 \\
Ambição escolar & 299 & $-2,1$ & 1,8 & 0,0 & 0,7 \\
Interação pais/ filhos & 299 & $-2,5$ & 2,0 & 0,0 & 0,9 \\
Escola pública comum & 101 & NSA & NSA & 33,8 & NSA \\
Escola pública quintil superior & 94 & NSA & NSA & 31,4 & NSA \\
Escola Federal & 35 & NSA & NSA & 11,7 & NSA \\
Escola privada & 69 & NSA & NSA & 23,1 & NSA \\
\hline
\end{tabular}

Fonte: Elaboração própria com dados da pesquisa.

Obs.: NSA - não se aplica. 


\section{Descrição dos modelos de regressão}

O modelo 1 tem a seguinte expressão:

Profic $_{i}=\beta_{0}+\beta_{1}(\mathrm{NSE})+\epsilon_{\mathrm{i}}$

Os parâmetros do modelo 1 têm os seguintes significados substantivos: a equação diz que a proficiência (Profic) em português de um aluno i pode ser descrita por meio de uma reta, na qual $\beta_{0}$ é o valor estimado da proficiência quando todas as variáveis independentes forem igual a zero. $\beta_{1}$ (NSE) é a mudança que ocorre na proficiência para cada mudança no NSE. $\epsilon_{\mathrm{i}}$ representa o termo de erro, ou seja, o que não é explicado pelas variáveis independentes.

No modelo 2, foram acrescidas as variáveis indicadoras do tipo de escola, produzindo a seguinte expressão:

Profic $_{i}=\beta_{0}+\beta_{1}(\mathrm{NSE})+\beta_{2}($ púb. destacada $)+\beta_{3}($ púb. federal $)+\beta_{4}($ privada) $+\epsilon_{\mathrm{i}}$

A interpretação difere, em relação ao modelo anterior, na leitura dos coeficientes das variáveis indicadoras do tipo de escola. Assim, o coeficiente de $\beta_{2}$ (pública destacada) é mudança que ocorre na proficiência de um aluno matriculado em escola pública destacada comparativamente à que ele teria se estivesse matriculado em uma escola pública comum. $\beta_{3}$ (pública federal) é mudança que ocorre na proficiência de um aluno matriculado na escola federal comparativamente à que ele teria se tivesse matriculado em uma escola pública comum. $\beta_{4}$ (privada) é mudança que ocorre na proficiência de um aluno matriculado em escola privada comparativamente à que ele teria se tivesse matriculado em uma escola pública comum. Sempre, mantendo o NSE constante.

Os demais modelos têm a mesma expressão, acrescentando-se, em cada um deles, um dos fatores. Por exemplo, a expressão do modelo que testou o fator "capital cultural objetivado" é a seguinte:

Profic $_{i}=\beta_{0}+\beta_{1}(\mathrm{NSE})+\beta_{2}($ pública destacada $)+\beta_{3}($ púb. federal $)+\beta_{4}$ (privada) $+\beta_{5}$ (cap. cult. obj.) $+\epsilon_{\mathrm{i}}$

O modelo final resulta de uma simulação computacional, e a expressão é equivalente ao último, mas com a inclusão de todos os fatores que permaneceram ao final do processo de ajuste. 


\section{ABSTRACT \\ Family Factors and School Performance: A Multidimensional Approach}

The article presents the results of a survey on family conditions and dynamics and their influence on children's performance in public and private primary schools in Belo Horizonte, Minas Gerais, Brazil. The data are from a survey of 299 families and children's proficiency tests produced by the Geres Project. Family-related variables were constructed and multivariate linear regression models were adjusted, starting from a basic model in which the outcome variable was proficiency in the Portuguese language, using family socioeconomic status and type of school as control variables. When analyzed singly, most factors were positively associated with school performance. The control variables and factors associated with the families' cultural capital prevailed when all were analyzed simultaneously. Type of school had a major impact on proficiency, with worse performance in public schools, thus confirming the unjust internal inequalities in the Brazilian school system.

Key words: school-family relationship; school inequalities; school performance

\section{RÉSUMÉ}

\section{Facteurs Familiaux et Performances Scolaires: Une Approche} Multidimensionnelle

Dans cet article, on présente les conclusions d'une enquête sur l'influence des conditions et des dynamiques familiales sur les résultats scolaires d'élèves de l'enseignement fondamental (entre 6 et 14 ans) public et privé à Belo Horizonte. Les données proviennent d'un sondage sur 299 familles et de tests de compétence réalisés par le Projet Geres. On a construit des facteurs se référant aux variables familiales et ajusté divers modèles de régression linéaire multiple, à partir d'un modèle de base dans lequel la variable réponse est la connaissance du portugais, ayant comme variables-contrôle le niveau socioéconomique des familles et le type d'école. La plupart des facteurs, de façon isolée, s'est montrée positivement associée aux performances scolaires. Les variables de contrôle et les facteurs associés au capital culturel des familles ont prévalu quand tous ont été analysés simultanément. On souligne l'effet du type d'école sur les compétences scolaires, ce qui confirme l'aspect pervers des inégalités internes du système d'éducation brésilien.

Mots-clés: rapport famille-école; inégalités scolaires; performances scolaires 